Irish Journal of Psychological Medicine, page 1 of 1 . (C) The Author(s), 2021. Published by Cambridge University Press on behalf of The College of Psychiatrists of Ireland.

CORRIGENDUM doi:10.1017/ipm.2021.58

\title{
Attempted suicide: does lethality matter? - Corrigendum
}

\section{A. M. Doherty ${ }^{1}$, S. Moore ${ }^{2}$, N. Corcoran ${ }^{3}$ and K. M. Malone ${ }^{2,4}$}

1 Psychiatry Registrar, St Patrick's University Hospital, Dublin, Ireland

${ }^{2}$ Consultant Liaison Psychiatrist, Department of Psychiatry, St Vincent's University Hospital, Dublin 4, Ireland

${ }^{3}$ Intern, Letterkenny University Hospital, Donegal, Ireland

${ }^{4}$ Dept. of Psychiatry, Psychotherapy \& Mental Health Research, UCD School of Medicine. St. Vincent's University, Elm Park, Dublin 4.

DOI: https://doi.org/10.1017/ipm.2021.50, Published online by Cambridge University Press, 12 July 2021

This article was published in the Irish Journal of Psychological Medicine with errors in the author name for N. Corcoran and the affiliation for K. M. Malone. This has now been corrected online and in the article.

The authors apologise for this error.

\section{Reference}

Doherty, A., Moore, S., Corcoran, N., \& Malone, K. (2021). Attempted suicide: Does lethality matter? Irish Journal of Psychological Medicine, 1-5. doi: 10.1017/ipm.2021.50 